\title{
Humanitarian Assistance and Disaster Relief mission by a tripartite medical team led by the Singapore Armed Forces after the $2015 \mathrm{Nepal}$ earthquake
}

Ming Li Leonard $\underline{\mathrm{Ho}}^{1}$, MBBS, FRCS, Jonathan Zhao Min Lim${ }^{1}$, MBBS, MMed, Mark Zhong Wei $\underline{\operatorname{Tan}}^{1}$, MBBS, Wai Leong Kok ${ }^{1}$, MBBS, MRCP, Jun Ren Zhang ${ }^{1}$, MBBS, MMed, Mian Yi $\underline{\operatorname{Tan}}^{1}$, MBBS, Adrian Chong Beng $\underline{\operatorname{Tan}}^{1}$, MBBS, FRCS

\begin{abstract}
INTRODUCTION This study aimed to report the injury or disease patterns, challenges, key observations, and recommendations by the Singapore Armed Forces (SAF) team that embarked on an Humanitarian Assistance and Disaster Relief (HADR) mission in the aftermath of the April 2015 Nepal earthquake.

METHODS The SAF medical team that provided HADR assistance to Nepal consisted of personnel from the SAF, Singapore's Ministry of Health and the Royal Brunei Armed Forces. Upon arrival in Kathmandu, Nepal, the SAF medical team was assigned to the Gokarna district by the local health authorities. In addition to providing primary healthcare, the medical facility was equipped to perform resuscitation and minor procedures. We also assembled mobile medical teams (MMTs) that travelled to various remote areas of the country to deliver medical aid.

RESULTS A total of 3,014 patients were managed by the SAF medical team. Of these patients, 1,286 (42.7\%) were men. $574(19.0 \%)$ patients sustained earthquake-related injuries or illnesses, while 2,440 (81.0\%) sustained non-earthquakerelated injuries or illnesses. The team treated a total of $447(77.9 \%)$ adults and $127(22.1 \%)$ paediatric patients with earthquake-related injuries or illnesses. A significant number of patients developed exacerbations of underlying medical conditions. $2,161(71.7 \%)$ patients were treated in our main facility in Gokarna, while 853 patients $(28.3 \%)$ were treated by our MMTs.

CONCLUSION The ability to transport healthcare personnel and essential medical equipment within a short time allowed the SAF medical team to provide crucial medical care in the aftermath of the 2015 Nepal earthquake.
\end{abstract}

Keywords: earthquake, healthcare after disasters, natural disasters, Nepal

\section{INTRODUCTION}

On 25 April 2015, an earthquake measuring 7.8 on the Richter scale struck Nepal. The epicentre of the earthquake was east of the district of Lamjung and its hypocentre had a depth of approximately $8.2 \mathrm{~km} .{ }^{(1,2)}$ This was the worst earthquake to strike Nepal since the 1934 Nepal-Bihar earthquake. This disaster killed more than 8,600 people in $\mathrm{Nepal}^{(3)}$ and injured more than twice as many. More than 450,000 people were displaced as a result of the earthquake. Houses were destroyed across many districts of the country and entire villages were flattened, especially those near the epicentre. ${ }^{(4)}$

To provide humanitarian assistance, the Singapore Armed Forces (SAF) deployed personnel to Nepal and led a tripartite medical team comprising healthcare personnel from the SAF, Singapore's Ministry of Health and the Royal Brunei Armed Forces. This 30-man team was made up of ten doctors, eight nurses, ten paramedics and two translators/liaison officers. The mission was to deliver medical aid and assistance to the earthquake victims. The aftermath of the earthquake saw a large commitment of medical support from multiple international agencies. Countries that provided help included neighbouring countries such as India. Europe, Malaysia and Singapore deployed medical teams. The distribution of medical assistance was coordinated by the United Nations Office for the Coordination of Humanitarian Affairs together with the local health authorities; their main centre of operations was the Multinational Military Coordination Center in Kathmandu.

Upon arrival in Kathmandu on 28 April 2015, the SAF medical team was assigned by the local health authorities to the Gokarna district. Gokarna is a suburban district located approximately $5 \mathrm{~km}$ from the city of Kathmandu. It has a population of about 10,000 people and was reported to be significantly damaged from the earthquake. However, major roads leading to Gokarna sustained only minor damage from the earthquake and remained open to vehicular access. Our medical team set up their living quarters in an airfield adjacent to Tribhuvan International Airport and commuted to Gokarna daily.

In Gokarna, the SAF medical team operated from a quadrangle located between the local temple and police headquarters. This location next to the police headquarters enabled the local authorities to provide security. Police officers assisted with crowd control and oversaw security of the facility, which was fully sheltered using Utilis tents (UTS S.A.S, Ennery, France) flown in from Singapore, and included areas for triage, consultation, treatment, resuscitation and the dispensary. As communication with patients was vital,

${ }^{1}$ Headquarters Medical Corps, Singapore Armed Forces, Singapore

Correspondence: Dr Ho Ming Li Leonard, Medical Officer, Headquarters Medical Corps, Singapore Armed Forces, 701 Transit Road, Singapore 778910. leonardhomingli@yahoo.com 
local volunteers acting as clinic translators were very helpful in facilitating the workflow in our medical facility. Apart from providing primary healthcare, our medical facility was equipped to perform resuscitation and minor procedures. Common procedures included manipulation and reduction of fractures, i.e. dislocations and wound debridement. Procedures were performed in well-lit conditions under moderate sedation and/or local anaesthetic blocks. Table I lists the essential equipment and drugs used during the mission.

Most musculoskeletal injuries incurred during an earthquake involve the extremities; ${ }^{(6,7)}$ this pattern of injury was also witnessed by our medical team. The team performed wound debridement and reduction of dislocated joints on several patients under moderate sedation, which was administered in the following steps:

a. Preparation: patients were counselled on the need for sedation and informed of the side effects of midazolam and ketamine. The medical team ensured that family/friends were available to take the patients home after the procedure.

b. Positioning: patients laid supine on a resuscitation bay stretcher and were given intranasal oxygen and an intravenous infusion of normal saline drip.

c. Monitoring: patients were monitored throughout the procedure via a Propaq ${ }^{\circledR}$ monitor (Welch Allyn, Skaneateles Falls, NY, USA) with electrocardiography, blood pressure and oxygen saturation monitoring.

d. Post-procedural recovery: patients were observed on stretchers until they regained consciousness and were able to ambulate independently. Moderate sedation was well-tolerated by the vast majority of patients and good analgesic effect was achieved during the procedure with no complaints of nausea or vomiting. After ketamine administration, side effects were observed in one elderly patient, who experienced euphoria and hallucinations lasting about one hour; this subsequently resolved on its own.

Patients requiring more advanced medical care or postprocedural radiography were referred to the district hospital, an hour's drive from Gokarna. Figs. 1-7 show the primary medical facility and mobile medical teams (MMTs).

Through interaction with the local populace, our team identified large pockets of casualties who were stranded in remote mountainous areas and had difficulty accessing medical aid. In order to reach these remote areas, an MMT was configured and transported to the remote areas via jeeps, while the rest of our medical team remained at the medical base in Gokarna, where we attended to the majority of patients. The MMT, comprising two medical officers, three nurses and/or paramedics, one driver and one local interpreter, was deployed to an area predetermined by the local health authorities every day. Information on the areas that most needed assistance was provided by the local police and Nepalese army. Transportation assets contributed by the Nepalese government (i.e. jeeps) allowed our team to commute to our area of operations, as well as deploy the MMT into remote regions of the country.
Table I. List of essential equipment and drugs.

\begin{tabular}{|c|c|}
\hline Equipment & $\begin{array}{l}\text { - Propaq® monitor } \\
\text { - Oxylator } \\
\text { - Ventilator (iVent) } \\
\text { - Electrocardiograph machine } \\
\text { - Nebuliser } \\
\text { - Defibrillator } \\
\text { - Oxygen concentrator } \\
\text { - Glucometer } \\
\text { - Generators } \\
\text { - Toilet and suture sets } \\
\text { - Plaster of Paris }\end{array}$ \\
\hline \multicolumn{2}{|l|}{ Drug } \\
\hline Resuscitation & $\begin{array}{l}\text { Adrenaline, amiodarone, dextrose } 50 \% \text {, } \\
\text { etomidate, propofol, thiopentone, } \\
\text { succinylcholine, atropine, normal saline, } \\
\text { Hartmann's solution, Gelofusine } ® \text {, salbutamol }\end{array}$ \\
\hline Analgesics & Morphine, ketamine, diclofenac, paracetamol \\
\hline CVS & Propranolol, nifedipine (Adalat $\circledast$ LA) \\
\hline Respiratory & $\begin{array}{l}\text { Salbutamol, dextromethorphan, } \\
\text { chlorpheniramine }\end{array}$ \\
\hline GIT & $\begin{array}{l}\text { Charcoal pills, Lomotil®, oral rehydration } \\
\text { salts, metoclopramide, famotidine }\end{array}$ \\
\hline Dermatological & $\begin{array}{l}\text { Combiderm } ® \text { cream, hydrocortisone cream, } \\
\text { urea cream, tetracycline ointment }\end{array}$ \\
\hline Antibiotics & $\begin{array}{l}\text { Amoxicillin, augmentin, cefazolin, } \\
\text { ceftriaxone, clarithromycin, metronidazole, } \\
\text { ciprofloxacin, doxycycline, clindamycin }\end{array}$ \\
\hline Sedation & Midazolam, diazepam, lorazepam \\
\hline
\end{tabular}

CVS: cardiovascular; GIT: gastrointestinal

\section{METHODS}

This article aimed to report patient demographics and disease patterns seen during the deployment, which can serve as additional information for medical teams planning future Humanitarian Assistance and Disaster Relief (HADR) missions. After attending to each patient, patient demographics, clinical history, physical examination findings, diagnosis and a management plan were recorded. The medical officers also assessed whether the patient's condition was earthquake-related. We defined an earthquake-related injury or illness (ERII) as one that resulted from physical trauma sustained during the earthquake or deteriorating environmental and sanitary conditions after the disaster (i.e. poor sanitation resulting in a gastroenteritis outbreak). The collected data was analysed at the end of the deployment.

\section{RESULTS}

The SAF medical team treated a total of 3,014 patients over nine days of operations. Patient demographics were as follows: 1,286 (42.7\%) men and 1,728 (57.3\%) women were treated; among them were $813(27.0 \%)$ paediatric patients (i.e. 0-18 years of age) and 2,201 (73.0\%) adult patients (defined as $>18$ years of age). 2,161 (71.7\%) patients were treated in our primary area of operations (Gokarna), while 853 (28.3\%) patients were treated by the MMTs.

$574(19.0 \%)$ patients sustained ERIls, which included $447(77.9 \%)$ adult and 127 (22.1\%) paediatric patients. Among the ERII patients, the most common conditions managed were 


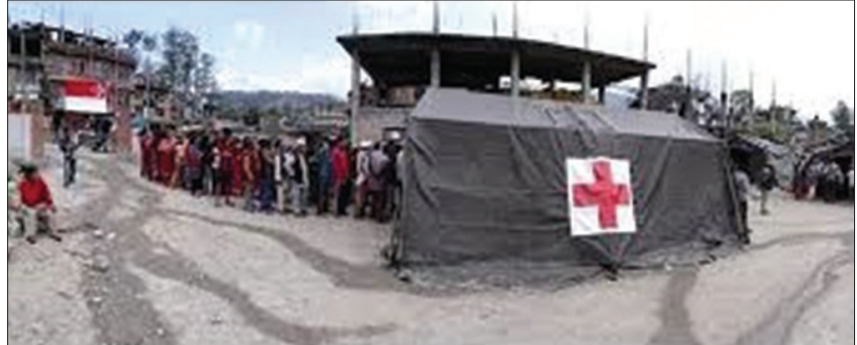

Fig. 1 Photograph shows the primary deployment site in the Gokarna district of Nepal.

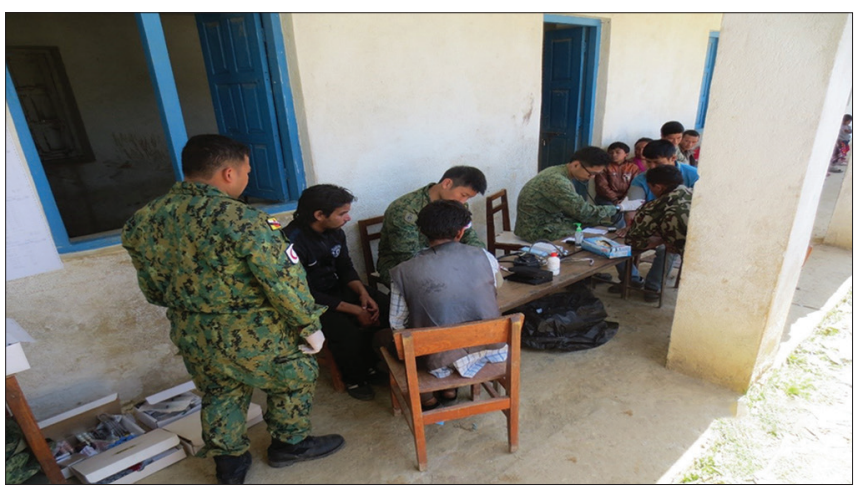

Fig. 2 Photograph shows the mobile medical team in operation.

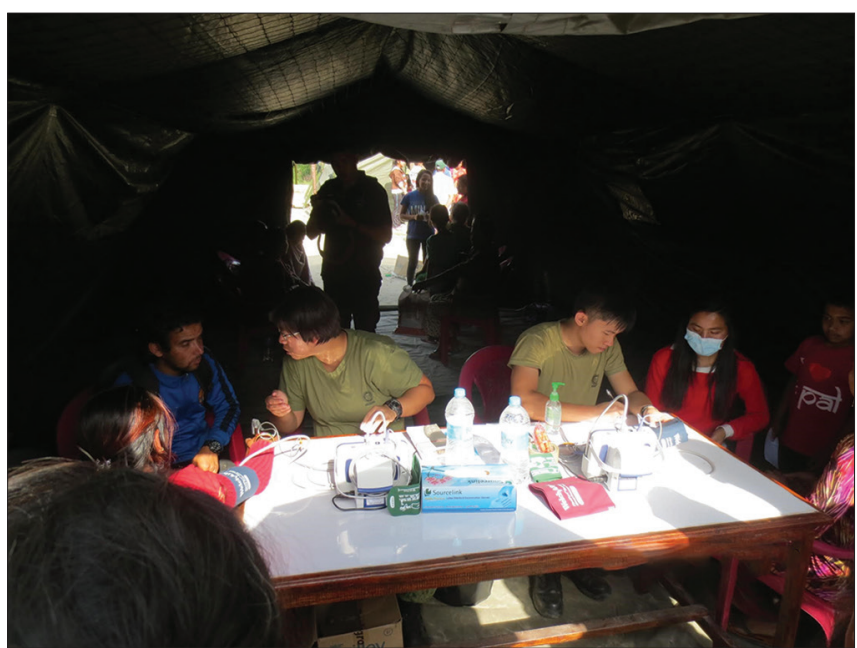

Fig. 3 Photograph shows the triage area.

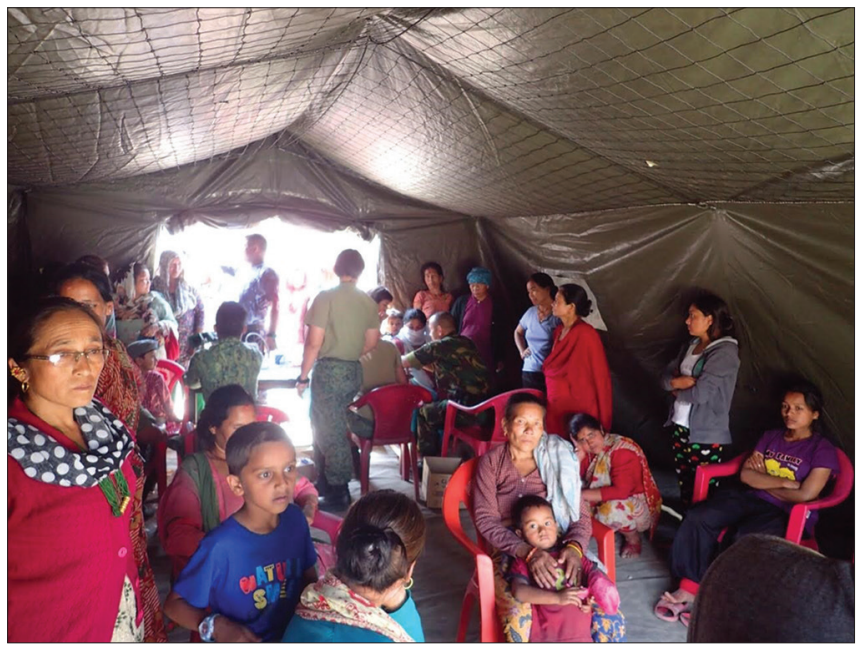

Fig. 4 Photograph shows the waiting area.

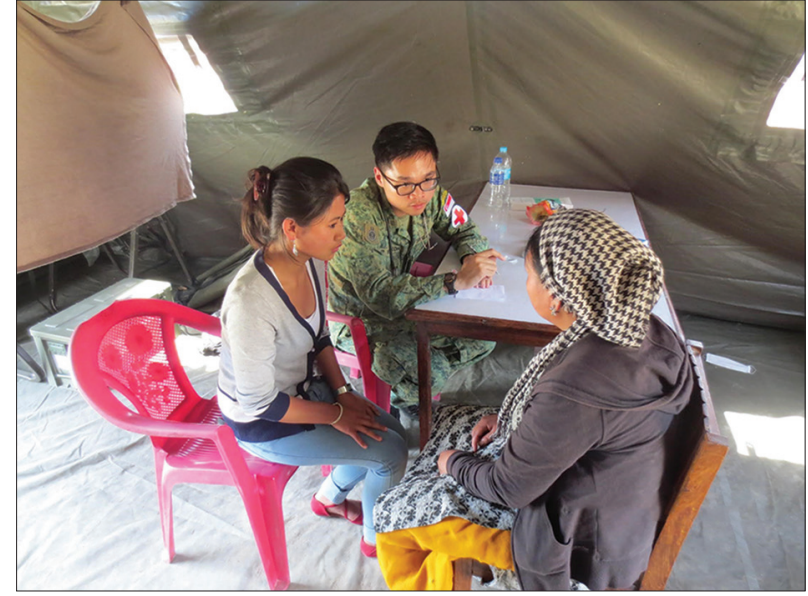

Fig. 5 Photograph shows the consultation area.

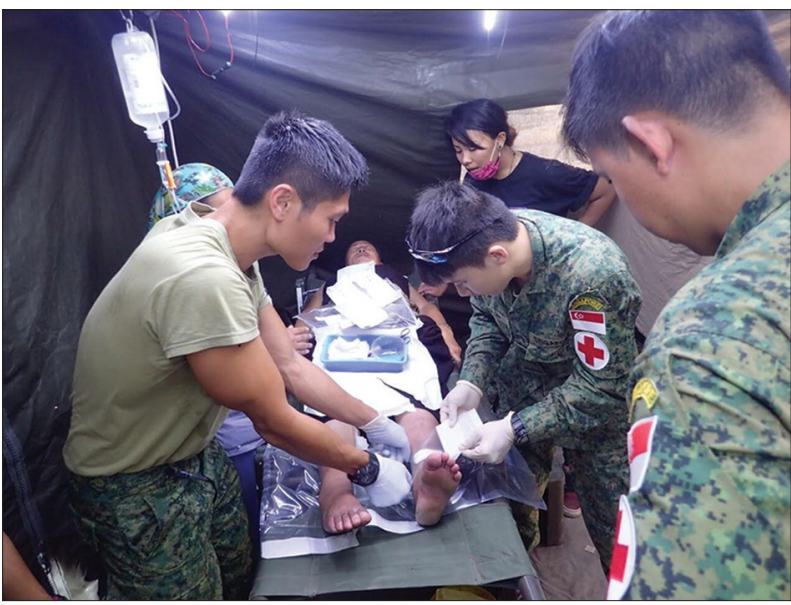

Fig. 6 Photograph shows the treatment area.

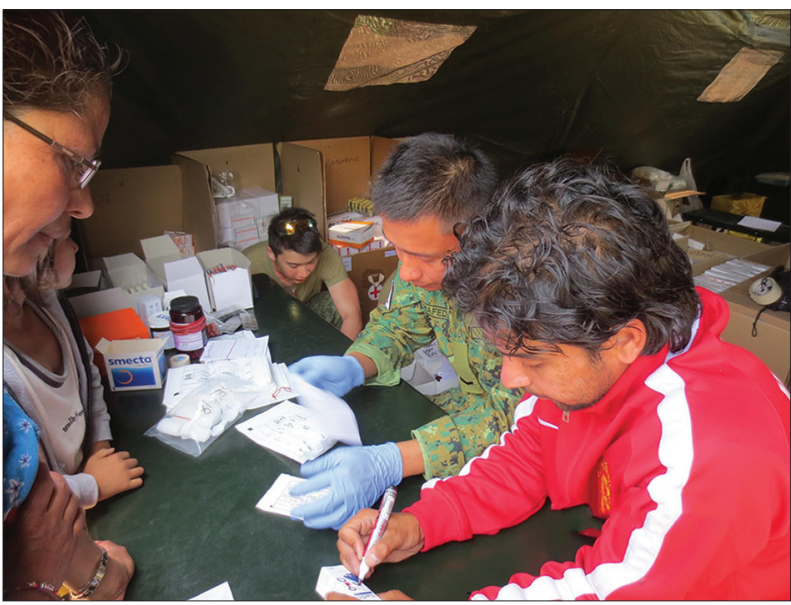

Fig. 7 Photograph shows the dispensary area.

Table II. Top five most common earthquake-related and non-earthquake-related injuries or illnesses.

\begin{tabular}{ll}
\hline Earthquake-related & Non-earthquake-related \\
\hline 1. Musculoskeletal & 1. Musculoskeletal \\
2. Respiratory & 2. Respiratory \\
3. Gastrointestinal & 3. Gastrointestinal \\
4. Dermatological & 4. Dermatological \\
5. Psychiatric & 5. Neurological \\
\hline
\end{tabular}




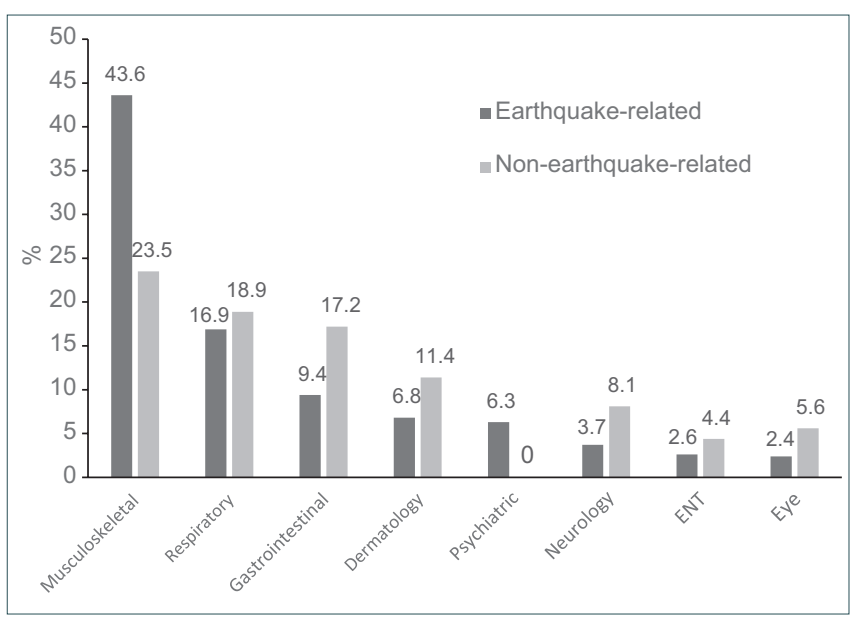

Fig. 8 Bar chart shows disease trends seen by the Singapore Armed Forces medical team. ENT: ear, nose and throat

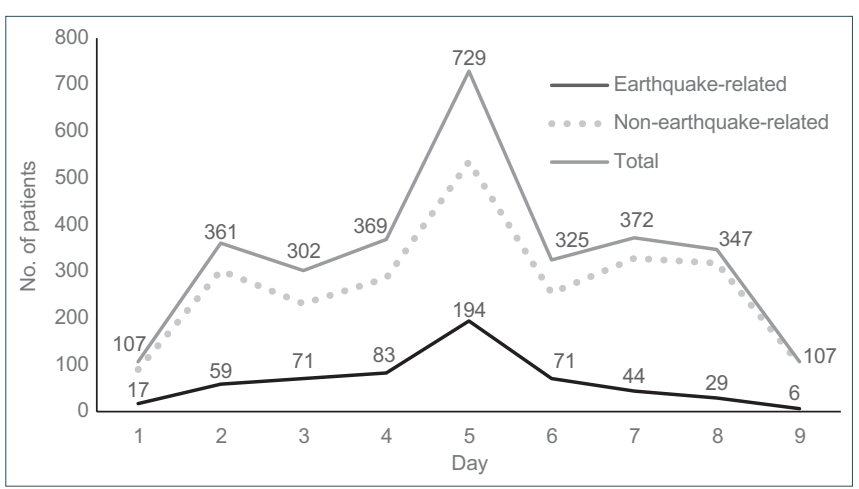

Fig. 9 Chart shows the number of patients seen per day of deployment. The horizontal axis refers to the days of operation of the Singapore Armed Forces medical team.

musculoskeletal injuries $(43.6 \%)$, followed by respiratory (16.9\%) and gastrointestinal (9.4\%) conditions. The majority of musculoskeletal injuries were lacerations, abrasions and fracture dislocations. A significant number of patients were treated for exacerbations of underlying medical conditions such as asthma and chronic obstructive pulmonary disease. The most common condition affecting adults with ERIls was musculoskeletal injuries, while that affecting paediatric patients was respiratory conditions. Notably, the team managed $36(6.3 \%)$ adults with psychiatric conditions such as post-traumatic stress disorder (PTSD) and depression (Fig. 8). No cases of meningitis, measles, dysentery or cholera were treated during deployment. Of the 2,440 patients treated for non-ERIIs, 1,847 (75.7\%) were adults and 593 (24.3\%) belonged to the paediatric age group. As in the ERII group, the most common diseases managed were musculoskeletal, respiratory and gastrointestinal in nature.

Patient demographics and disease patterns were similar for patients with ERIIs and non-ERIIs. Non-ERII patients outnumbered ERII patients. Patients with musculoskeletal injuries formed a much larger proportion of the ERII group than the non-ERII group (43.6\% vs. $23.5 \%$ ). Table II shows the top five most common ERIIs and non-ERIls.

The proportion of patients with ERIIs increased steadily during the first five days of operations and reached a peak

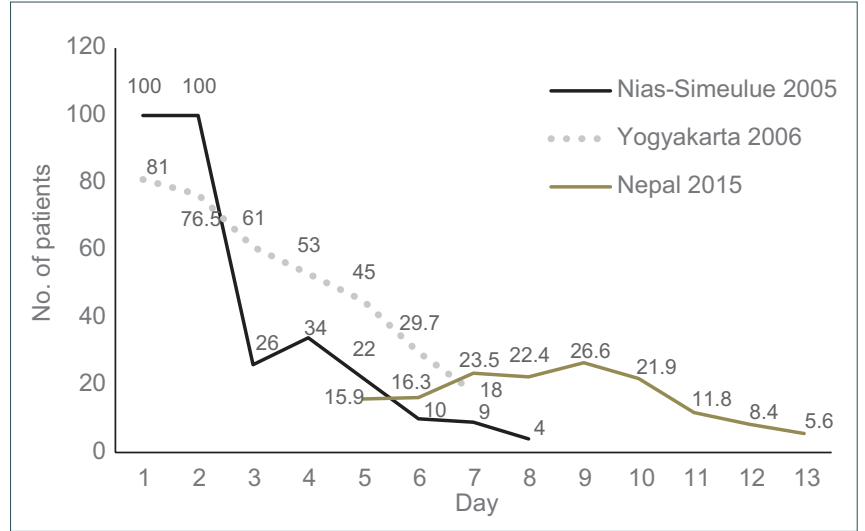

Fig. 10 Chart shows earthquake-related injuries or illnesses seen in Nepal during this period compared to other recent Singapore Armed Forces medical deployments after an earthquake.

on Day 5 (Fig. 9). After Day 5, the proportion of patients with ERIls decreased. We found that the proportion of patients with ERIIs is lower compared to that seen in previous SAF medical deployments after an earthquake. Fig. 10 shows the comparison of the proportion of patients with ERIls in Nepal with two other most recent SAF medical team deployments after earthquakes, namely the Nias-Simeulue earthquake (2005) and the Yogyakarta earthquake (2006).

During the initial days of medical operations after the 2005 Nias-Simeulue earthquake, all patients presented with ERIls, but this number tapered dramatically within the week. Likewise, for the 2006 Yogyakarta earthquake, a similar pattern was seen. However, for the Nepal deployment, the proportion of patients presenting with ERIIs was significantly less than the other two earthquakes at the start and middle of the deployment period.

\section{DISCUSSION}

In a landmark paper in 1983, Trunkey described a trimodal distribution of trauma deaths based on the time interval from injury to death. ${ }^{(8)}$ About $50 \%$ of deaths occur in the first hour from sustaining overwhelming/non-survivable injuries and another $30 \%$ occur within four hours from sustaining severe trauma/bleeding. The timeliness of medical care administered during each of these crucial time points impacts the outcome. The nature of injuries and patient profiles encountered by medical teams in an earthquake zone is determined by the timing of the team's deployment in relation to the occurrence of the earthquake.

Approximately 14 major earthquakes of magnitude 7.0 to 7.9 and one earthquake of magnitude 8.0 or above occur worldwide per year. ${ }^{(9)}$ Compared to other disasters, earthquakes carry the highest risk of severe damage and injury. Many factors contribute to the level of damage caused, including population density and the degree of urbanisation in the affected area. Furthermore, an earthquake is not a single event with a defined endpoint; it tends to produce a series of events (i.e. widespread damage to housing and sanitation) that continues to affect lives over a prolonged period. Overall, the most common ERIls are musculoskeletal in nature and are often associated with significant mortality. 
Injuries have high-impact mechanisms, frequently involving multiple systems and requiring intensive surgical care at a time when local medical response capacities are stretched. Other health issues, such as overcrowding in temporary shelters, can lead to outbreaks of infectious diseases, such as gastrointestinal outbreaks.

We reasoned that the difference in the proportion of ERIIs seen by the SAF medical team in Nepal compared to that seen by the Nias-Simeulue and Yogyakarta teams is likely due to the fact that the medical team started operations five days after the earthquake occurred, when many casualties had already received medical aid. The timing of our deployment also explained the injury profiles, such as infected wounds and neglected fractures.

Based on the Nias-Simeulue and Yogyakarta disasters, we would expect the proportion of patients with ERIls to decrease with time. However, the percentage of ERII patients in Nepal increased before declining on Day 6. A possible explanation is that the mountainous terrain in Nepal delayed casualties from accessing medical care. Using the MMTs, we were able to reach and treat such patients who had ERIls, adding to the proportion of patients with ERIIs.

From both the ERII and nERII groups, the most commonly affected systems were the musculoskeletal, respiratory and gastrointestinal systems. To facilitate planning for future disaster deployments, the medical supplies of medical teams should include equipment (i.e. toilet and suture sets, plaster of Paris, moderate sedation drugs, etc) and medication that are useful in treating these conditions. Medical staff should also be prepared to treat patients in the paediatric age group, as they often form a sizable percentage of patients. Lastly, although these were not encountered during the Nepal deployment, we advise future medical teams to be prepared in managing common obstetric conditions, particularly deliveries.

Psychiatric issues are commonly overlooked in the aftermath of a mass disaster. Common psychiatric conditions following an earthquake include PTSD and anxiety attacks. General distress levels following an earthquake appear to return to normal after about 12 months, but PTSD reactions do not fade until 18 months after the earthquake. ${ }^{(10)}$ During our deployment, about $6.3 \%$ of earthquake casualties suffered from psychiatric conditions such as PTSD and anxiety attacks.

Overall, the experience working together was a positive one that was built on well-considered working principles. Although the team was under the ambit of the SAF, it was made up of civilians and military personnel from different nationalities and cultural backgrounds. Members of the SAF medical team worked cohesively with one another despite their diverse backgrounds and deployment at short notice. The increased manpower and medical equipment from the composite team translated to the capability to manage more casualties. Exchanges between team members enabled them to share knowledge and better understand each organisation or country's culture and work processes, as well as promoting defence relations between countries. The importance of exercising patience, maintaining open channels of communications and keeping an open mind cannot be overemphasised. To promote healthy team dynamics, team leaders ensured that each component of the medical facility (including the MMTs) was made up of members from different nationalities and agencies. It was critical to maintain a balance between ensuring operational discipline and collegiality; although some issues demanded strict compliance, such as those pertaining to personal safety, team members were encouraged to give as much input as possible on other issues (e.g. individual welfare).

Sustenance and communications were well-planned. From our camp near the Tribhuvan International Airport, the SAF medical team maintained close communication with our headquarters in Singapore to ensure the timely replenishment of medical supplies and other essential equipment. To mitigate personnel fatigue from the fast working pace, shift systems were implemented to ensure maximal staff morale and work rate.

However, there were areas for improvement. In this mission, the various medical subgroups were deployed into theatre by their respective ministries and governments at slightly different timings. In future multi-organisation deployments, it would be useful for all team members to familiarise themselves with the logistics and work processes of the different organisations so that the management of patients is as seamless as possible. Fortunately, the team was able to quickly work around the differences to deliver quality medical care to the earthquake victims. We also learnt that pockets of earthquake victims could be stranded in mountainous regions and unable to seek medical help due to the severity of their injuries. Most of these regions were only accessible by air or extended land travel using cross-country fourwheel drive vehicles. Unfortunately, our medical team did not have the necessary transportation assets or equipment to negotiate the deep mountain terrain safely to deliver much-needed medical care to these victims.

Lastly, to respond rapidly to the mission, the team was required to manage multiple issues at every phase of deployment, ranging from manpower to logistics. Data collection for the purpose of scientific study was not a key priority and it was anticipated that team members would have minimal capacity to perform this task. The unfamiliar spoken language in Nepal meant additional effort was needed to ensure accurate translation and data collection. However, should such a requirement arise for future HADR missions, we recommend that the study design be formulated prior to deployment and specific team members assigned the duty of accurate data collection and analysis during the deployment.

The SAF has had many previous experiences with the rapid deployment of medical teams to provide timely HADR aid to disaster areas. With its ability to transport healthcare personnel and essential medical equipment within a short time, the SAF medical team comprising members of the SAF, Singapore's Ministry of Health and the Royal Brunei Armed Forces provided crucial medical care in the aftermath of the 2015 Nepal earthquake. 


\section{ACKNOWLEDGEMENTS}

We would like to thank COL (Dr) Poon Beng Hoong, COL (Dr) Lo Hong Yee, and LTC (Dr) Vernon Lee for their valuable input.

\section{REFERENCES}

1. United States Geological Survey (USGS). Magnitude 7.8 Earthquake in Nepal and Aftershocks [online]. Available at: www.usgs.gov/blogs/features/ usgs_top_story/magnitude-7-8-earthquake-in-nepal/. Accessed January 30, 2016.

2. Galetzka J, Melgar D, Genrich JF, et al. Slip pulse and resonance of the Kathmandu basin during the 2015 Gorkha earthquake, Nepal. Science 2015; 349:1091-5.

3. Incident Report of Earthquake 2015. In: Nepal Disaster Risk Reduction Portal [online]. Available at: drrportal.gov.np. Accessed January 30, 2016.

4. National emergency Operation Centre Nepal Govt. report. 25 April 2015. In: Nepal Disaster Risk Reduction Portal [online]. Available at: www.drrportal.gov.np/uploads/document/329.pdf. Accessed January 30, 2016.
5. Nepal earthquake: SAF plane to ferry aid, medical personnel and searchand-rescue team to Nepal. The Straits Times 2015 Apr 25.

6. Mulvey JM, Awan SU, Qadri AA, Maqsood MA. Profile of injuries arising from the 2005 Kashmir earthquake: the first 72 h. Injury 2008; 39:554-60.

7. Bulut M, Fedakar R, Akkose S, et al. Medical experience of a university hospital in Turkey after the 1999 Marmara earthquake. Emerg Med J 2005; 22:494-8.

8. Trunkey DD. Trauma. Accidental and intentional injuries account for more years of life lost in the U.S. than cancer and heart disease. Among the prescribed remedies are improved preventive efforts, speedier surgery and further research. Sci Am 1983; 249:28-35.

9. United States Geological Survey (USGS). Are Earthquakes Really on the Increase? Earthquake Hazards Program [online]. Available at: http:// earthquake.usgs.gov/earthquakes/eqarchives/year/eqstats.php. Accessed on January 30, 2016.

10. Carr VJ, Lewin TJ, Webster RA, Kenardy JA. A synthesis of the findings from the Quake Impact Study: a two-year investigation of the psychosocial sequelae of the 1989 Newcastle earthquake. Soc Psychiatry Psychiatr Epidemiol 1997; 32:123-36. 